\title{
SEMI-ACTIVE VIBRATION CONTROL OF HORIZONTAL SEAT SUSPENSION BY USING MAGNETO-RHEOLOGICAL DAMPER
}

\author{
Igor Maciejewski, Tomasz Krzyżý́ski, Sebastian Pecolt, Sebastian Chamera \\ Koszalin University of Technology, Faculty of Technology and Education, Koszalin, Poland \\ e-mail: igor.maciejewski@tu.koszalin.pl; tomasz.krzyzynski@tu.koszalin.pl, sebastian.pecolt@tu.koszalin.pl; \\ sebastian.chamera@tu.koszalin.pl
}

\begin{abstract}
In this paper, the modelling process and control strategy of a semi-active seat suspension with a magneto-rheological damper (MR) is presented. The proposed system should protect operators of working machines against vibration in the horizontal direction. The control algorithm mimics the desired force that might be introduced into the seat suspension actively. The model parameters are determined experimentally as a function of the control current. The elaborated system is tested by using an electro-hydraulic shaker that generates vibrations for the semi-active seat suspension with the seated human body. Power spectral densities and transmissibility functions are presented as the results of simulations and measurements. In addition, transmissibility factors and maximum relative displacements of the suspension are evaluated for both the conventional passive seat suspension and the semi-active system with an MR damper.
\end{abstract}

Keywords: vibration isolation, MR damper, semi-active control

\section{Introduction}

A lot of research works in semi-active damping systems assume that the damping force can be controlled by mechanical changing of the damper orifice using hydraulic valves. These valves are expensive, noisy and slow in operation due to time delay. As the technology advances, semi-active damping systems using smart fluids with an adjustable viscosity to control the damper damping force, instead of hydraulic valves, enjoy a considerable attention.

Smart fluid dampers are classified into two types electro-rheological (ER) and magneto-rheological (MR) dampers. These fluids can reversibly instantaneously change from a free-flowing liquid to a semi-solid with controllable yield strength when exposed to a magnetic field or electric current. MR fluid damper have been used in seat suspensions for trucks since 1998 in USA and, recently, in production of the main suspension of passenger cars (El-Kafafy et al., 2012). In the paper (Lai and Liao, 2002), the authors found that MR fluids could be designed to be very effective vibration control actuators. In the article by Orecny et al. (2014), two alternatives of semi-active suspensions of the seat of a working machine was shown. An MR damper was used in the first case, and in the second case the suspension of the seat was a combination of a magneto-rheological damper and a dynamic absorber. In both cases, the dampers were controlled by the sky-hook algorithm.

An MR damper that consists of a fixed orifice damper filled with an MR fluid is an device having a significant potential for mechanical control applications. Due to non-linear characteristics, its inverse dynamics model is difficult to obtain. The paper by Spencer et al. (1997) presents a phenomenological model of an MR-damper which is based on the Bouc-Wen hysteresis model that is capable of exhibiting a wide variety of hysteretic behavior. In the paper (Choi et al., 2001), a hysteresis model for the field-dependent damping force of the MR damper was proposed. The 
damping force was compared with the predicted ones from the Bingham model, Bouc-Wen model and the proposed polynomial model. It was demonstrated there that the polynomial model predicted well the non-linear hysteresis behavior of the MR damper. A different approach was presented in another paper (Jin et al., 2001), which was non-linear black-box structure to model the MR damping behavior on the displacement-velocity phase plane. Two constructive parameter estimation algorithms were subsequently developed basing on the current mathematical advances in wavelets and ridgelets analysis. Compared with the traditional physical modeling, that research aimed at improving the model numerical stability and model structure generality. In (Tsang et al., 2006), the Simplified Inverse Dynamics (SID) model was developed for both the Bingham plasticity model and the Bouc-Wen hysteresis model. SID models were then used to calculate the optimal fluid yield stress or input current in order to realise the desirable control forces obtained from various optimal control algorithms.

A lot of research has been made in the field of suspending seats and cars by using magneto-rheological semi-active dampers. The results showed great improvements in reducing vibrations (Segla, 2012; Choi et al., 2000). The aim of this work is to present an original methodology of the control synthesis that allows one to define the control system structure of a semi-active seat suspension. In particular, the paper suggests application of the control system which is based on the inverse dynamics of a magneto-rheological damper.

\section{Design of the control system of the horizontal suspension with the seated human body}

In Fig. 1, a physical model of the horizontal seat suspension with the seated human body is shown. A simple 3-DOF model is employed to describe the biodynamic response of the system the seated human body and cushioned seat (Stein et al., 2007). The object of vibration isolation is assumed as a lumped mass body which consists of three interconnected masses by means of linear springs and dampers. The first mass $m_{1}$ is used to model the seat upper part frame, whereas the next masses depict the sitting parts of the human body. The mass $m_{2}$ describes the human body part in contact with the back support and the mass $m_{3}$ represents the human body part moving freely without any support. In accordance with the presented model, evaluation of the human exposure to whole-body vibration is considered in the horizontal $x$-direction. The mechanical vibrations are generated by using the kinematic excitation $q_{s x}$ of the system.
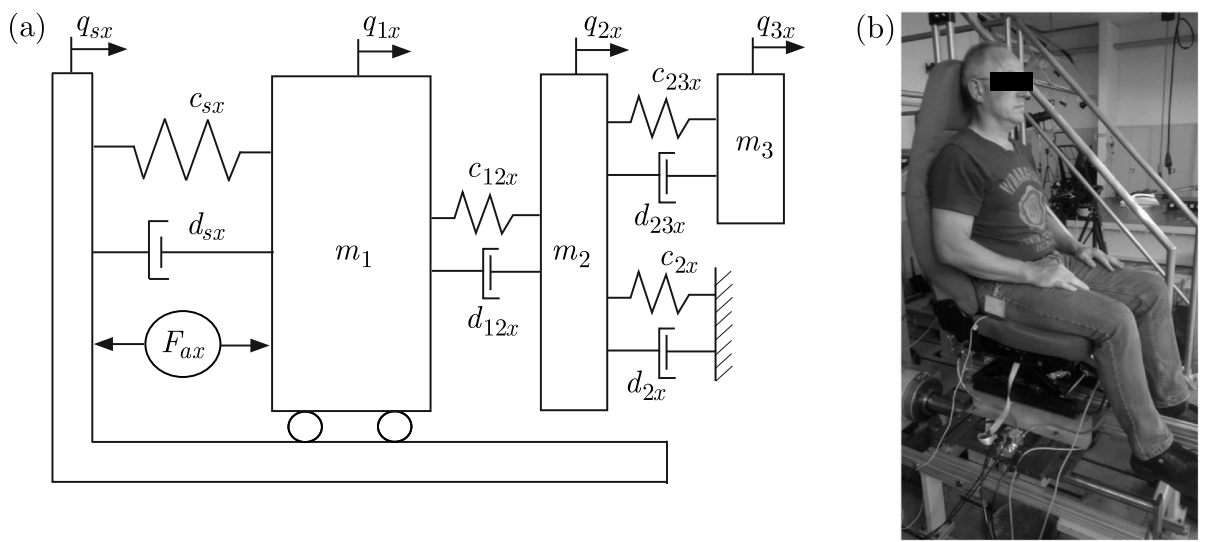

Fig. 1. Physical model of the active horizontal seat suspension with the seated human body (a) and the laboratory experimental set-up (b)

In order to evaluate the desired force that should be generated in the system actively, the linear spring $c_{s x}$ and damper $d_{s x}$ are employed to describe essential characteristics of the ho- 
rizontal seat suspension. The linear suspension system can be modelled using a state space approach for the purpose of primary controller synthesis. The following state variables are used to represent the movement of the human body in the longitudinal $x$-direction

$$
\mathbf{x}_{x}(t):=\left[q_{1 x}, \dot{q}_{1 x}, q_{2 x}, \dot{q}_{2 x}, q_{3 x}, \dot{q}_{3 x}\right]^{\mathrm{T}}
$$

where: $q_{1 x}, q_{2 x}, q_{3 x}$ and $\dot{q}_{1 x}, \dot{q}_{2 s}, \dot{q}_{3 x}$ are the displacements and velocities of the bio-mechanical model (Fig. 1a). The external disturbances are defined as the displacement $q_{s x}$ and velocity $\dot{q}_{s x}$ of the input vibration

$$
\mathbf{w}_{s x}(t):=\left[q_{s x}, \dot{q}_{s x}\right]^{\mathrm{T}}
$$

The state-space equation of the active horizontal suspension is obtained using the applied force $F_{a x}$ as an output from the primary controller

$$
\dot{\mathbf{x}}_{x}(t)=\mathbf{A}_{x} \mathbf{x}_{x}(t)+\mathbf{B}_{s x} \mathbf{w}_{s x}(t)+\mathbf{B}_{a x} F_{a x}(t)
$$

The state (system) matrix is formulated in the following form

$$
\mathbf{A}_{x}=\left[\begin{array}{cccccc}
0 & 1 & 0 & 0 & 0 & 0 \\
-\frac{c_{11 x}}{m_{1}} & -\frac{d_{11 x}}{m_{1}} & \frac{c_{12 x}}{m_{1}} & \frac{d_{12 x}}{m_{1}} & 0 & 0 \\
0 & 0 & 0 & 1 & 0 & 0 \\
\frac{c_{12 x}}{m_{2}} & \frac{d_{12 x}}{m_{2}} & -\frac{c_{22 x}}{m_{2}} & -\frac{d_{22 x}}{m_{2}} & \frac{c_{2 n i}}{m_{2}} & \frac{d_{2 n i}}{m_{2}} \\
0 & 0 & 0 & 0 & 0 & 1 \\
0 & 0 & \frac{c_{23 x}}{m_{3}} & \frac{d_{23 x}}{m_{3}} & -\frac{c_{33 x}}{m_{3}} & -\frac{d_{33 x}}{m_{3}}
\end{array}\right]
$$

The following input matrices are given for the seat suspension system

$$
\mathbf{B}_{s x}=\left[\begin{array}{cc}
0 & 0 \\
\frac{c_{s x}}{m_{1}} & \frac{d_{s x}}{m_{1}} \\
0 & 0 \\
0 & 0 \\
0 & 0 \\
0 & 0
\end{array}\right] \quad \mathbf{B}_{a x}=\left[\begin{array}{c}
0 \\
\frac{1}{m_{1}} \\
0 \\
0 \\
0 \\
0
\end{array}\right]
$$

The selected damping $d_{11 x}, d_{22 x}, d_{33 x}$ and stiffness $c_{11 x}, c_{22 x}, c_{33 x}$ coefficients should be calculated using the following relations

$$
\begin{array}{ll}
d_{11 x}=d_{12 x}+d_{s x} & c_{11 x}=c_{12 x}+c_{s x} \\
d_{22 x}=d_{2 x}+d_{12 x}+d_{23 x} & c_{22 x}=c_{2 x}+c_{12 x}+c_{23 x} \\
d_{33 x}=d_{23 x} & c_{33 x}=c_{23 x}
\end{array}
$$

The output vector contains the isolated body acceleration $\ddot{q}_{1 x}$ and the suspension travel $q_{1 x}-q_{s x}$ in order to assess the system performance

$$
\mathbf{z}_{x}(t):=\left[\ddot{q}_{1 x}, q_{1 x}-q_{s x}\right]^{\mathrm{T}}
$$

Using such a system configuration, the output equation can be written as

$$
\mathbf{z}_{x}(t)=\mathbf{C}_{1 x} \mathbf{x}_{x}(t)+\mathbf{D}_{1 s x} \mathbf{w}_{s x}(t)+\mathbf{D}_{1 a x} F_{a x}(t)
$$


where the corresponding output matrix is described as follows

$$
\mathbf{C}_{1 x}=\left[\begin{array}{cccccc}
-\frac{c_{11 x}}{m_{1}} & -\frac{d_{11 x}}{m_{1}} & \frac{c_{12 x}}{m_{1}} & \frac{d_{12 x}}{m_{1}} & 0 & 0 \\
1 & 0 & 0 & 0 & 0 & 0
\end{array}\right]
$$

In succession, the feedforward matrices are given as

$$
\mathbf{D}_{1 s x}=\left[\begin{array}{cc}
\frac{c_{s x}}{m_{1}} & \frac{d_{s x}}{m_{1}} \\
-1 & 0
\end{array}\right] \quad \mathbf{D}_{1 a x}=\left[\begin{array}{c}
1 \\
m_{1} \\
0
\end{array}\right]
$$

The system configuration presented in this paper requires measuring of the suspension travel $q_{1 x}-q_{s x}$ and the absolute velocity $\dot{q}_{1 x}$ of the isolated body. Therefore, the measurement vector can be expressed as

$$
\mathbf{y}_{x}(t):=\left[q_{1 x}-q_{s x}, \dot{q}_{1 x}\right]^{\mathrm{T}}
$$

The corresponding measurement equation reads

$$
\mathbf{y}_{x}(t)=\mathbf{C}_{2 x} \mathbf{x}_{x}(t)+\mathbf{D}_{2 s x} \mathbf{w}_{s x}(t)+\mathbf{D}_{2 a x} F_{a x}(t)
$$

with the following matrices

$$
\begin{aligned}
& \mathbf{C}_{2 x}=\left[\begin{array}{llllll}
1 & 0 & 0 & 0 & 0 & 0 \\
0 & 1 & 0 & 0 & 0 & 0
\end{array}\right] \\
& \mathbf{D}_{2 s x}=\left[\begin{array}{cc}
-1 & 0 \\
0 & 0
\end{array}\right] \quad \mathbf{D}_{2 a x}=\left[\begin{array}{l}
0 \\
0
\end{array}\right]
\end{aligned}
$$

The desired active force is finally determined by using the following relation

$$
F_{a x}(t)=\mathbf{K}_{x} \mathbf{y}_{x}(t)
$$

where $\mathbf{K}_{x}=\left[k_{1 x}, k_{2 x}\right]$ is the output feedback gain vector to be determined. The desired active force (Eq. (2.14)) has to be reproduced using the controlled element, i.e. by the MR damper device with variable damping characteristics.

\subsection{Model of the magneto-rheological damper}

The MR damper is a controllable shock-absorber willingly used for vibration reduction in automotive suppression applications. Such a damper is filled with a magneto-rheological fluid that is controlled by an external magnetic field. The damping force can be changed very fast by varying the electric current that flows through the coil windings. In most applications (Zipser et al., 2001), the solenoids are placed around the orifice between chambers $A$ and $B$ of the damper (Fig. 2). However, the proposed MR damper is built utilizing an outer bypass due to lack of space inside the single-tube damper concept with a small diameter piston. The controllable current changes properties of the fluid flow and, in consequence, the force of the damper is regulated.

In order to model the hysteretic force-velocity characteristics of the MR damper, a model proposed in the paper (Kwok et al., 2006) is employed. Such a model contains viscous damping, spring stiffness and a hysteretic component as follows

$$
F_{m r}=d_{m r}\left(\dot{q}_{1 x}-\dot{q}_{s x}\right)+c_{m r}\left(q_{1 x}-q_{s x}\right)+\alpha_{m r} z_{m r}+f_{m r}
$$

where $F_{m r}$ is the MR damper force, $q_{1 x}-q_{s x}$ and $\dot{q}_{1 x}-\dot{q}_{s x}$ are the relative displacement and velocity of the damper, $d_{m r}$ is the viscous damping coefficient, $c_{m r}$ is the stiffness coefficient, 


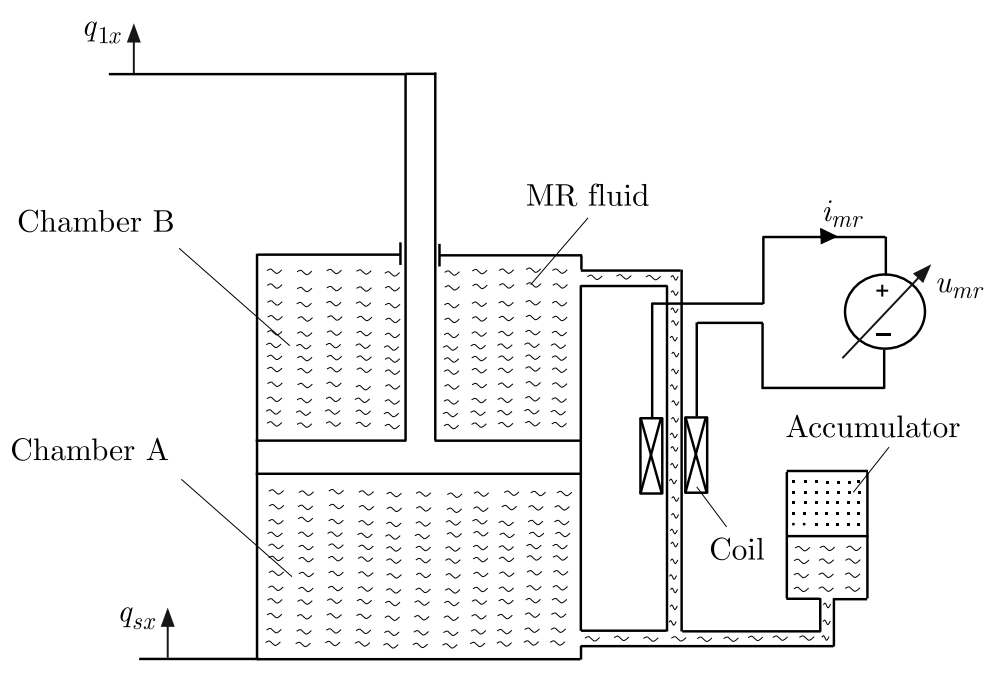

Fig. 2. MR damper structure

$\alpha_{m r}$ is the scale factor of the hysteresis, $z_{m r}$ is the hysteretic variable, $f_{m r}$ is the force offset. The hysteretic variable can be given by the hyperbolic tangent function (Kwok et al., 2006)

$$
z_{m r}=\tanh \left(\beta_{m r}\left(\dot{q}_{1 x}-\dot{q}_{s x}\right)+\delta_{m r} \operatorname{sgn}\left(q_{1 x}-q_{s x}\right)\right)
$$

where $\beta_{m r}$ and $\delta_{m r}$ are the model parameters describing the shape of the hysteresis. The unknown model parameters are evaluated by means of the identification experiment that is graphically illustrated in Fig. 3a. The sinusoidal cycling of the MR damper is applied with an amplitude of $12.5 \mathrm{~mm}$ and a frequency of $1.8 \mathrm{~Hz}$. The tests are performed at a constant current flowing through the coil windings, i.e. linearly increasing from 0 up to the maximum permissible operating current $4 \mathrm{~A}$. In Fig. 3b, some selected force characteristics of the MR damper are presented.

(a)
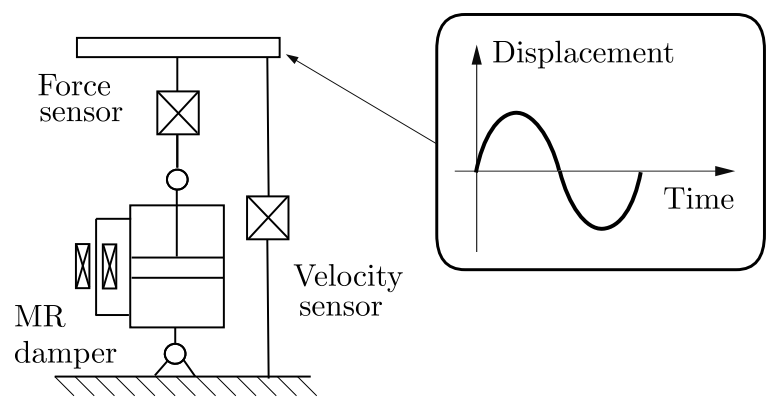

(b)

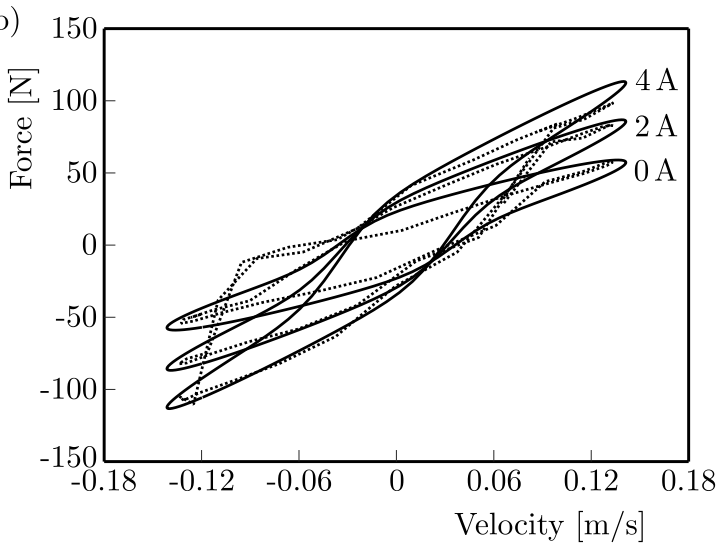

Fig. 3. Experimental set-up for evaluation of the MR damper force (a), force characteristics of the MR damper at constant values of the current flowing through coil windings (b) obtained using the simulation model (-) and measurement (...)

The proposed identification procedure applies the least square error minimisation technique over the considered velocity range. The error minimisation includes model parameters having an influence on the MR damper force characteristics as follows

$$
\min _{d_{m r}, c_{m r}, \alpha_{m r}, f_{m r}, \beta_{m r}, \delta_{m r}} \sqrt{\sum_{i=1}^{n}\left(F_{m r}\left(\dot{q}_{1 i}-\dot{q}_{s i}\right)_{i}-\widehat{F}_{m r}\left(\dot{q}_{1 x}-\dot{q}_{s x}\right)_{i}\right)^{2}}
$$


where $F_{m r}$ and $\hat{F}_{m r}$ are the simulated and measured MR damper forces that are obtained for the same velocity values $\left(\dot{q}_{1 x}-\dot{q}_{s x}\right)_{i}$.

As resulting from the performed identification procedure, the following model parameters: $c_{m r}, f_{m r}, \beta_{m r}, \delta_{m r}$ have fixed values regardless of different input currents from the range of 0-4 A. The other model parameters, i.e. viscous damping $d_{m r}$ and scale factor of the hysteresis $\alpha_{m r}$, are variables in function of the control current $i_{m r}$. For this reason, the polynomial regression is employed to estimate the appropriate parameters: $d_{m r}, \alpha_{m r}$ of the analytical model (Maciejewski et al., 2014)

$$
d_{m r}=a_{1} i_{m r}+a_{0} \quad \alpha_{m r}=b_{2} i_{m r}^{2}+b_{1} i_{m r}+b_{0}
$$

where $a_{1}, a_{0}$ and $b_{2}, b_{1}, b_{0}$ are the polynomial coefficients determined for a specific type of an MR damper. The viscous damping coefficient $d_{m r}$ and scale factor of the hysteresis $\alpha_{m r}$ are shown in Fig. 4 as a function of the input current $i_{m r}$.
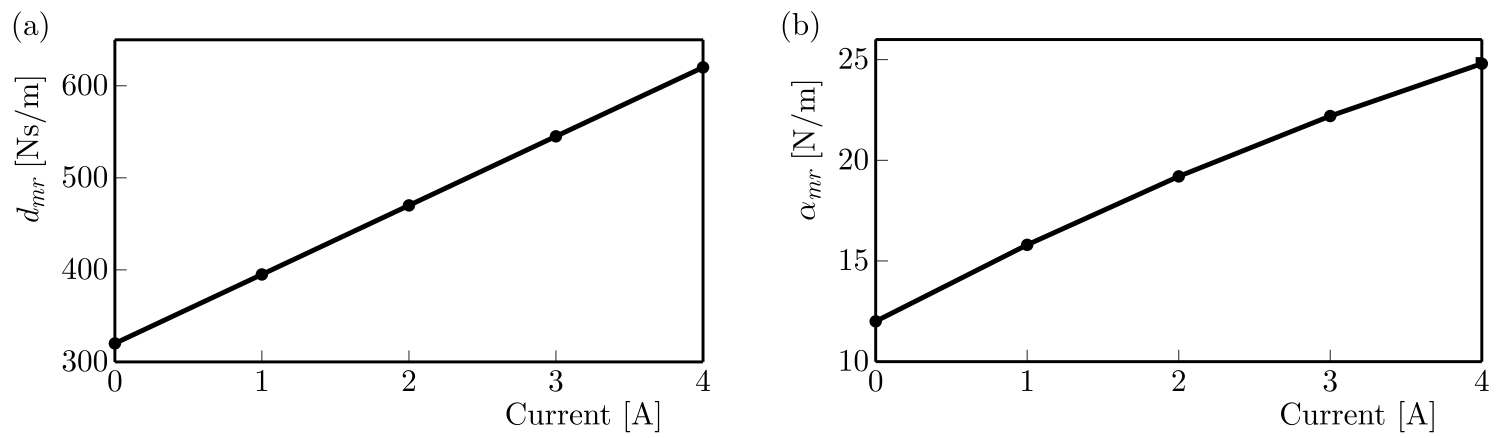

Fig. 4. Measured (-) and approximated (•) viscous damping coefficient $d_{m r}$ and scale factor of the hysteresis $\alpha_{m r}$ as a function of the input current

The MR damper dynamics is described by using the first order inertial element (Tarnowski, 2001) with the time constant $t_{m r}$. The following function is used in order to model the system delay in response to the electrical control signal $u_{m r}$

$$
t_{m r} \dot{i}_{m r}+i_{m r}=k_{m r} u_{m r}
$$

where $k_{m r}$ is the static gain of the MR damper. Each parameter used in the MR damper model is shown in Table 1.

\subsection{Inverse model of the MR damper}

If the MR damper model is determined (see previous Section), the desired force $F_{a x}$ can be partially obtained by injecting an appropriate current $i_{m r}$ into the coil windings in accordance with the actual piston displacement $q_{1 x}-q_{s x}$ and velocity $\dot{q}_{1 x}-\dot{q}_{s x}$. The controlled current is calculated from Eqs. (2.15)-(2.18) using the following relations

$$
i_{m r}=\frac{-a_{1}\left(\dot{q}_{1 x}-\dot{q}_{s x}\right)-b_{1} z_{m r}+\operatorname{sgn}\left(z_{m r}\right) \sqrt{\Delta}}{2 b_{2} z_{m r}}
$$

with a function $\Delta$ that is calculated as

$$
\begin{aligned}
\Delta= & {\left[a_{1}\left(\dot{q}_{1 x}-\dot{q}_{s x}\right)+b_{1} z_{m r}\right]^{2} } \\
& -4 b_{2} z_{m r} t\left[a_{0}\left(\dot{q}_{1 x}-\dot{q}_{s x}\right)+c_{m r}\left(q_{1 x}-q_{s x}\right)+b_{0} z_{m r}+f_{m r}-F_{a x}\right]
\end{aligned}
$$

where $F_{a x}$ is the desired MR damper force, $c_{m r}$ is the stiffness coefficient, $z_{m r}$ is the hysteretic variable given by Eq. (2.16), $f_{m r}$ is the force offset, $a_{1}, a_{0}$ and $b_{2}, b_{1}, b_{0}$ are the polynomial coefficients expressed with respect to the input current (see Eqs. (2.18)). 
Table 1. Parameter values used in the MR damper model

\begin{tabular}{|l|c|c|}
\hline \multicolumn{1}{|c|}{ Parameter } & Value & Unit \\
\hline \hline Stiffness coefficient $c_{m r}$ & 1000 & $\mathrm{~N} / \mathrm{m}$ \\
\hline Force offset $f_{m r}$ & 0 & $\mathrm{~N}$ \\
\hline $\begin{array}{l}\text { First parameter shaping force hysteresis } \\
\text { of MR damper } \beta_{m r}\end{array}$ & 40 & $\mathrm{~s} / \mathrm{m}$ \\
\hline $\begin{array}{l}\text { Second parameter shaping force hysteresis } \\
\text { of MR damper } \delta_{m r}\end{array}$ & 1.4 & $1 / \mathrm{m}$ \\
\hline $\begin{array}{l}\text { First polynomial coefficient approximating } \\
\text { viscous damping of MR damper } a_{0}\end{array}$ & 320 & $\mathrm{Ns} / \mathrm{m}$ \\
\hline $\begin{array}{l}\text { Second polynomial coefficient approximating } \\
\text { viscous damping of MR damper } a_{1}\end{array}$ & 75 & $\mathrm{Ns} /(\mathrm{Am})$ \\
\hline $\begin{array}{l}\text { First polynomial coefficient approximating } \\
\text { scale factor of hysteresis } b_{0}\end{array}$ & 12 & $\mathrm{~N}$ \\
\hline $\begin{array}{l}\text { Second polynomial coefficient approximating } \\
\text { scale factor of hysteresis } b_{1}\end{array}$ & 4 & $\mathrm{~N} / \mathrm{A}$ \\
\hline $\begin{array}{l}\text { Third polynomial coefficient approximating } \\
\text { scale factor of hysteresis } b_{2}\end{array}$ & -0.2 & $\mathrm{~N} / \mathrm{A}^{2}$ \\
\hline Actuating time $t_{m r}$ & 0.01 & $\mathrm{~s}$ \\
\hline Static gain $k_{m r}$ & 1 & $\mathrm{~A} / \mathrm{V}$ \\
\hline
\end{tabular}

In Fig. 5, a graphical representation of the MR damper inverse model is shown. It should be noted that the MR damper is a semi-active device and the desired force $F_{a x}$ can be realised only if this force and the damper velocity have the same sign. Then the calculated input signal of the $\mathrm{MR}$ damper varies in the range of $0 \mathrm{~A}$ (minimum value) and $4 \mathrm{~A}$ (maximum value) and depends on the actual value of the desired MR damper force and its actual velocity. If the desired force and damper velocity have opposite signs then the input signal is settled to zero.

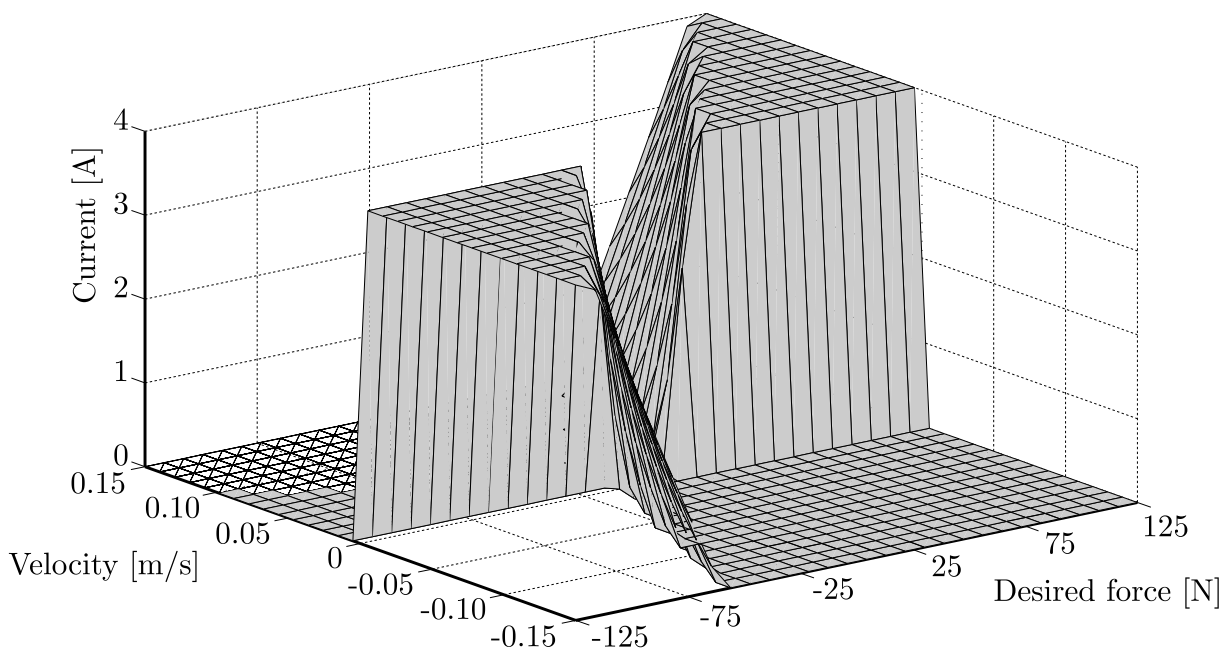

Fig. 5. Inverse model of the MR damper at different values of the desired force and suspension velocity

In the following paper, it is assumed that the controlled current $i_{m r}$ is proportional to the voltage input signal $u_{m r}$ using the programmable power supply. In order to eliminate the actuating time $t_{m r}$ of MR damper, the voltage input signal is calculated by the predictor PD as follows 


$$
u_{m r}=\frac{1}{k_{m r}}\left(t_{m r} \dot{i}_{m r}+i_{m r}\right)
$$

where $k_{m r}$ is the static gain of the MR damper, $u_{m r}$ is the control signal. The electric input signal for the MR damper is then limited to the operating range

$$
u_{c}=\left\{\begin{array}{lll}
u_{\min } & \text { for } & u_{m r}<u_{\min } \\
u_{m r} & \text { for } & u_{\min } \leqslant u_{m r}<u_{\max } \\
u_{\max } & \text { for } & u_{m r} \geqslant u_{\max }
\end{array}\right.
$$

where $u_{\min }$ is the minimum input voltage that is responsible for the lowest damping force, $u_{\max }$ is the maximum input voltage that is required to generate the highest damping force.

\section{Laboratory investigation of the semi-active seat vibration control}

An electro-hydraulic shaker is utilized as an actuator that provides a random vibration source for testing and analysis. The seated human with body mass $90 \mathrm{~kg}$ is used for the tests (see Fig. 1b). The tested person sits comfortably on a seat cushion with an integrated backrest. The vertical suspension system is locked, therefore, the shocks and vibration affecting the occupants of working machines can be reduced by using the horizontal seat suspension that is under examination. The male subject is exposed to random whole-body vibration in the longitudinal $x$-direction. For the purpose of evaluating the system vibro-isolation properties, the excitation signal similar to white, band limited noise in the range of frequency $0.5-10 \mathrm{~Hz}$ is applied at three different excitation intensities: WN1x $\left(1.02 \mathrm{~m} / \mathrm{s}^{2}\right)$, WN2x $\left(1.36 \mathrm{~m} / \mathrm{s}^{2}\right)$ and $\mathrm{WN} 3 \mathrm{x}\left(1.91 \mathrm{~m} / \mathrm{s}^{2}\right)$. The obtained power spectral densities and transmissibility functions of the horizontal suspension system are presented in Fig. 6.

As shown in Fig. 6, the semi-active seat suspension considerably reduces human exposure to harmful effects of vibration in comparison with the passive system. Lower amplitudes of the human vibration are observed in the considered frequency range between 0.5 and $10 \mathrm{~Hz}$. Numerical values of the transmissibility factors $\mathrm{TFE}_{x}$ and suspension travels $s_{t x}$ obtained for excitation signals: WN1x, WN2x and WN3x are presented in Table 2.

Table 2. Numerical values of the transmissibility factors and suspension travels obtained for excitation signals: WN1x, WN2x, WN3x and human body mass $90 \mathrm{~kg}$

\begin{tabular}{|c|c|c|c|c|}
\hline \multirow{2}{*}{$\begin{array}{c}\text { Input } \\
\text { vibration }\end{array}$} & \multicolumn{2}{|c|}{ Passive } & \multicolumn{2}{c|}{ Semi-active } \\
\cline { 2 - 5 } & $\begin{array}{c}\mathrm{TFE}_{x} \\
\text { factor }\end{array}$ & $\begin{array}{c}s_{t x}, \\
{[\mathrm{~mm}]}\end{array}$ & $\begin{array}{c}\mathrm{TFE}_{x} \\
\text { factor }\end{array}$ & $\begin{array}{c}s_{t x} \\
{[\mathrm{~mm}]}\end{array}$ \\
\hline \hline WN1x & 1.050 & 18.2 & 0.810 & 25.8 \\
\hline WN2x & 1.046 & 25.1 & 0.810 & 38.5 \\
\hline WN3x & 1.071 & 28.2 & 0.891 & 43.5 \\
\hline
\end{tabular}

The measured vibro-isolation criteria (see Table 2) demonstrate the improved system effectiveness due to semi-active control of the MR damper. The transmissibility factors $\mathrm{TFE}_{x}$ are lower by about $20 \%$ as compared to the conventional passive system, however the system performance decreases with an increase in the excitation intensity. The suspension travel $s_{t x}$ of the active system have a little larger values in comparison with the passive system, therefore, a higher suspension stroke is recommended for the semi-active vibration isolator. 

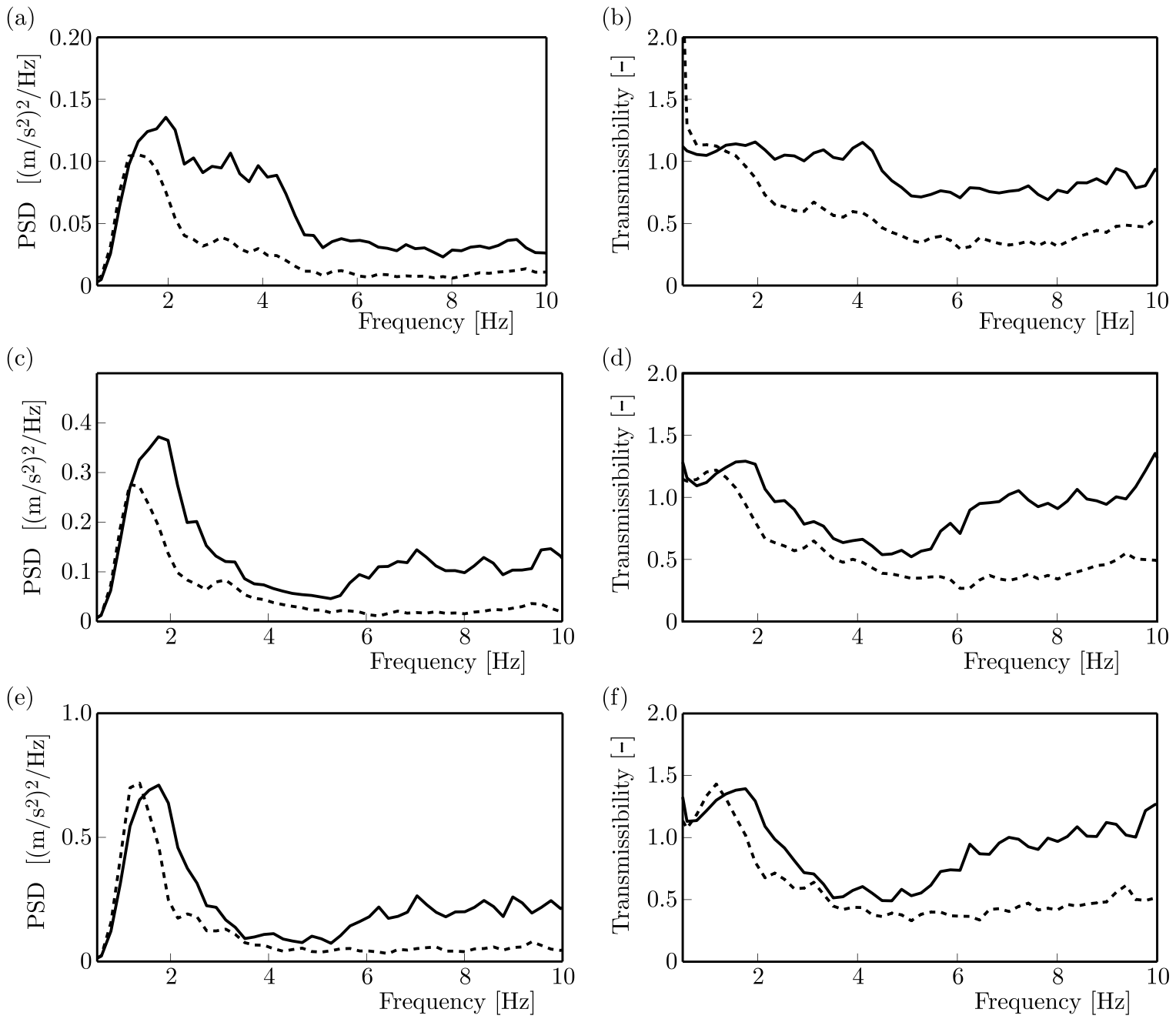

Fig. 6. Power spectral densities and transmissibility functions of the passive $(-)$ and semi-active ( $\cdots)$ horizontal seat suspension at different intensities of the excitation signals: WN1x (a)-(b), WN2x (c)-(d), WN3x (e)-(f), human body mass $90 \mathrm{~kg}$

\section{Conclusions}

The implementation of a novel control strategy applied to the horizontal seat suspension system allows one to reduce harmful vibrations transmitted to the driver in a wide range of excitation frequencies. The following paper includes the authors' proposal of modeling the MR damper device, the state space approach for the purpose of primary controller synthesis, the inverse model of the MR damper at different values of the desired force and suspension velocity as well as successful experimental verification of the semi-active system. Better vibro-isolation properties for the excitation signals with different vibration intensities are obtained using a semi-active system in comparison with the passive one. The measurement results with a test person indicate reasonable advantages of the demonstrated control strategy in the frequency range $0.5-10 \mathrm{~Hz}$.

\section{Acknowledgements}

The following work is a part of the research project "Methods and procedures of selecting vibro-isolation properties of vibration reduction systems" founded by the National Science Center of Poland under the contract No. UMO-2013/11/B/ST8/03881. 


\section{References}

1. El-Kafafy M., El-Demerdash S.M., Rabeih A.M., 2012, Automotive ride comfort control using MR fluid damper, Engineering, 4, 4, 179-187

2. LAi C.Y., LiaO W.H., 2002, Vibration control of a suspension system via magneto rheological fluid damper, Journal of Vibration and Control, 8, 4, 527-547

3. Orecny M., Sega S., Hunady R., Ferkova Z., 2014, Application of a magneto-rheological damper and a dynamic absorber for a suspension of a working machine seat, Procedia Engineering, 96, 338-344

4. Spencer B.F., Dyke S.J., Sain M.K., Carlson J.D., 1997, Phenomenological model for magnetorheological dampers, Journal of Engineering Mechanics, 123, 3, 230-238

5. Choi S.B., Lee S.K. PArK Y.P., 2001, A hysteresis model for the field-dependent damping force of a magnetorheological damper, Journal of Sound and Vibration, 245, 2, 375-383

6. Jin G., Sain M.K., Pham K.D., Spencer B.F., Ramallo J.C., 2001, Modeling MR-dampers: a nonlinear blackbox approach, Proceedings of the American Control Conference, 1, 429-434

7. Tsang H.H., Su R.K.L., Chandler A.M., 2006, Simplified inverse dynamics models for MR fluid dampers, Engineering Structures, 28, 3, 327-341

8. Segla S., 2012, Modelling and optimization of the half model of a passanger car with magnetorheological suspension system, Advances in Mechanisms Design, Mechanisms and Machine Science, 8, 429-435

9. Choi S.B., NAm M.H., Lee B.K., 2000, Vibration control of a MR seat damper for commercial vehicles, Journal of Intelligent Materials and Structures, 11, 12, 936-944

10. Stein G.J, Muka P., Chmurny R., Hinz B., Bluthner R., 2007, Measurement and modelling of $x$-direction apparent mass of the seated human body - cushioned seat system, Journal of Biomechanics, 40, 1493-1503

11. Zipser L., Richter L., Lange U., 2001, Magnetorheological fluids for actuators, Sensors and Actuators A: Physical, 92, 318-325

12. Kwok M.M., Ha Q.P., Nguyen T.H., Li J., Samali B., 2006, A novel hysteretic model for magnetorheological fluid dampers and parameter identification using particle swarm optimization, Sensors and Actuators A, 132, 441-451

13. Maciejewski I., Krzyzynski T., Meyer L., 2014, Control system synthesis of seat suspensions used for protection of working machine operators, Vehicle System Dynamics, 52, 11, 1355-1371

14. Tarnowski W., 2001, Simulation and Optimisation in Matlab (in Polish), Intergraf S.C., Sopot 